\title{
Hypertrophy of the appendices epiploicae and lipomatous polyposis of the colon
}

\author{
VALENTINE A. J. SWAIN, WINIFRED F. YOUNG, AND \\ ELIZABETH M. PRINGLE
}

From the Queen Elizabeth Hospital for Children, London

\section{CASE REPORT}

J.W. (male) was born one month post mature of an otherwise normal pregnancy weighing $2.7 \mathrm{~kg}$. After breast feeding for three months he gained only $0.9 \mathrm{~kg}$ and after changing to a full-cream, dried-milk mixture he continued to gain weight very slowly. At 5 months he started to vomit and a hiatus hernia being suspected he was given thickened feeds and placed in a 'hiatus' chair. Although he still looked wasted his weight had reached $7 \cdot 8 \mathrm{~kg}$ (above the 10 th percentile). Subsequently, he again put on weight slowly, in spite of his mother's statement that he had an enormous appetite which could never be satisfied, in comparison with the five older children in the family.

At 2 years 3 months he was admitted to hospital for failure to thrive, presenting as a pale, red-haired cheerful boy with marked wasting but weighing $10.5 \mathrm{~kg}$ (above the third percentile). He was unable to walk, and spoke very little, and had abdominal distension which had been increasing for the previous nine months. He had had bouts of diarrhoea for three months and his stools were still dark and loose. There had been no alimentary disturbance affecting any of the rest of the family.

Investigations showed that fat was $42 \%$ of the dried faeces. However, one month later the daily excretion of fat was estimated to be only $2.6 \mathrm{~g}$. Urinary xylose excretion was normal. High amounts of trypsin were present in the stools excluding pancreatic insufficiency. Except for a haemoglobin level of $9.8 \mathrm{~g}$ per $100 \mathrm{ml}$ all other investigations, including serum electrophoresis and urine chromatography, gave normal results.

He was given a gluten-free diet and although he gained weight at first, this gain was not sustained, and his nutrition was still very poor at 4 years. His mother agreed that there had been lapses in the diet. It was therefore decided to examine the jejunal mucosa for the changes typical of gluten enteropathy and he was transferred to the Queen Elizabeth Hospital for a biopsy to be obtained. Figure 1 shows that J.W. was wasted and had abdominal distension at this time. However, his weight and height were both approximately the same percentile. Two lipomata were noted, one about $5 \mathrm{~cm}$ in diameter in the right axilla, and another about $7.5 \mathrm{~cm} \times 5 \mathrm{~cm}$ in the right lumbar region. Microscopical examination of the jejunal mucosa and its disaccharidase levels were normal. In view of the recent consumption of gluten, gluten enteropathy was thus excluded.

Abdominal palpation was still negative but a straight radiograph of the abdomen showed a diffuse opacity in the anterior abdominal cavity displacing the bowel shadows. As the child contracted infective hepatitis an operation was not performed until two months later (19 October 1964) following a severe attack of abdominal colic lasting one hour. At laparotomy, along the whole length of the colon the appendices epiploicae were grossly enlarged enveloping most of its surface, and those attached to the loop of pelvic colon presented as a bulky mass which was lightly adherent to the lateral abdominal wall. The rest of the contents of the abdomen appeared normal; the small intestine was of normal calibre and appearance (Fig. 2). The fat of the omentum and that of the mesentery of the bowel was normally distributed. One of the appendices epiploicae $(3 \times 1 \times 1 \mathrm{~cm})$ was removed

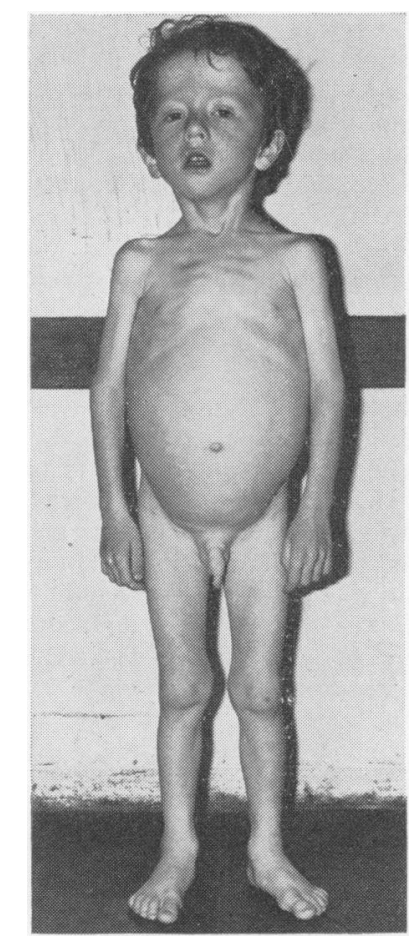

FIG. 1. J.W. aged 4 years 1 month. 


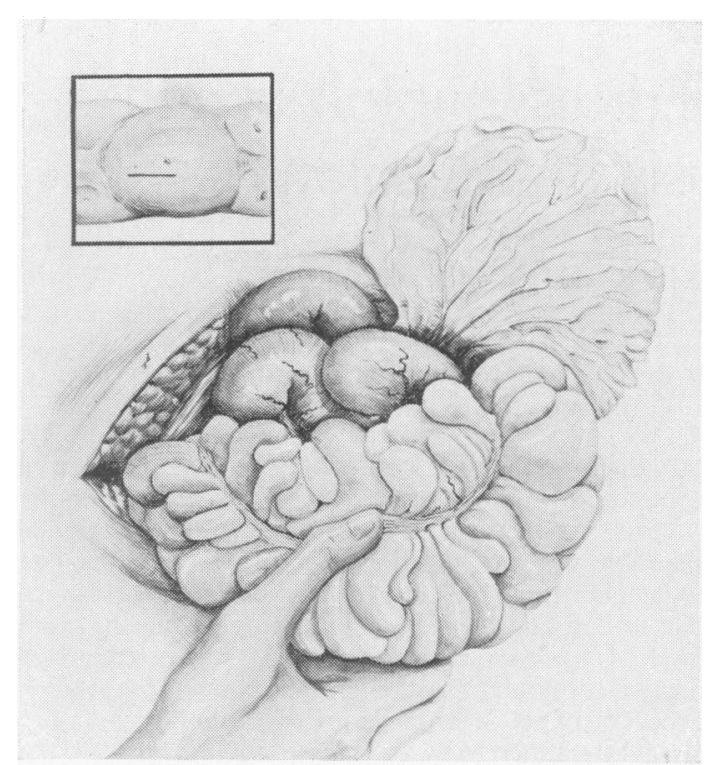

FIG. 2. J.W. Laparotomy: pelvic colon exposed to show grossly enlarged appendices epiploicae.

for microscopy and was found to be normal. Following the operation he had no further attacks of abdominal colic.

A barium meal showed no sign of intrinsic small bowel disease, but the small intestine was seen to be misplaced upwards and to the right, presumably by the masses of fatty appendices epiploicae of the pelvic colon; however, a barium enema showed that the mucosa of the large bowel was polypoid throughout especially in the pelvic colon (Fig. 3). Sigmoidoscopy revealed a uniform 'polyposis' above the anorectal line and the mucosal surface was smooth without signs of ulceration. It was demonstrated microscopically that the polypi resulted from depositions of fatty tissue in the mucosa and submucosa.

For two months while in hospital after the laparotomy he was given selected easily assimilable foods to provide high calories and protein but a restricted fat intake, together with iron and vitamin supplements. At home he remained well, active, and cheerful with a good appetite, but only gained weight slowly. However, his mother had partially altered his food back to the more bulky family meals, but had continued to give the supplements.

At 6 years 4 months he was still very thin and both lipomata had regressed. His abdomen was less distended, and his stools were said to be normal, but his weight and height remained on the third percentile. On an approximately normal fat intake, only $1.7 \mathrm{~g}$ fat and $14.1 \mathrm{~g}$ dry weight were excreted in the faeces daily, and there seemed no good reason for advising a stricter diet. Aged 8 years he was fit and doing well at school. He was not anaemic and his weight was on the third percentile while his height had nearly reached the 10th percentile, and his skeletal age was not significantly retarded ( 7 years).

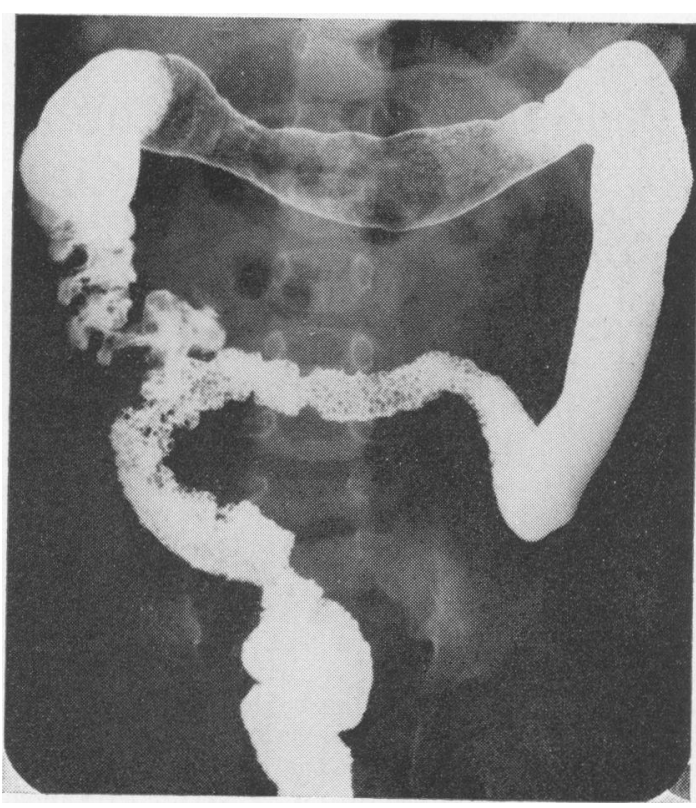

FIG. 3. J.W. Barium enema showing polypoid appearance of the colon especially in the pelvic loop.

\section{DISCUSSION}

In 1957, a similar case to that described here was reported from the Mayo Clinic (Godenne, Burke, and Hallenbeck, 1957). Their case of 'epiploic lipomatosis' was a 3-year-old boy with a protuberant abdomen which suggested coeliac disease or mesenteric cyst. The stools contained excess of fat, and small amounts of microscopic oil and fatty acid crystals. A radiograph showed that the small intestine was situated in the right upper abdominal quadrant, suggesting displacement by a lesion such as an internal hernia or intraperitoneal cyst. At operation huge fatty tags were found on the splenic flexure and descending colon. Though radiologically the colon was in normal position the mucosal lining was not demonstrated. This boy made a good recovery and at the age of 11 years he was 'completely normal except for his protuberant abdomen', he was 'as vigorous and active as anyone else his age, and doing well at school'. His physiological systems all seemed to be functioning normally, but he had a 'craving for chocolate and salt' (Lynn, 1964).

In our case (J.W.) enlargement of the appendices epiploicae involved the whole length of the colon; also the mucosal lining had an unusual 'polypoid' appearance radiologically and the discovery of collections of fat in the mucosa and submucosa microscopically are two additional findings to those described in the Mayo Clinic patient. 
As regards the terminology of this condition, 'epiploic lipomatosis' is an attractive title but may give the wrong impression that the omentum (epiploön) is involved. It is suggested that a 'hypertrophy of the appendices epiploicae' more accurately describes the massive enlargement of the fatty 'dog ears' which is characteristic of this disease.

As the history suggests that the condition was present at birth and there has been no evidence of subsequent disproportionate growth, it is probable that the intestinal condition represents an adipose hamartoma. This view is supported by the fact that the lipomata of the back and axilla have not shown any sign of progression and may even have regressed. There was no family history of hamartomata.

Without evidence of persisting malabsorption it is difficult to explain the child's poor weight record. The massive hypertrophy of the fatty tags on the surface of the colon can hardly account for any digestive upset except by the mechanical effect of its great bulk. It is more likely that the changes in the mucosa and submucosal lining could play a part. The short-term prognosis appears good, except that the abdomen will remain prominent.

\section{SUMMARY}

The unique case of a boy with massive hypertrophy of the appendices epiploicae of the whole colon, and underlying the mucosa and submucosa a polypoid appearance due to a collection of fatty tissue, has been described.

He presented with abdominal distension and failure to thrive and variable alimentary symptoms. Coeliac disease was suspected and disproved. The diagnosis was made at operation. The prognosis seems to be favourable. It is suggested that the condition represents an adipose hamartoma.

We are indebted to Dr J. Luder for referring this interesting case and for the early hospital records; to Dr Basil Morson for advice on the histological appearances; to $\mathrm{Dr}$ N. E. France and Dr E. Ann Burgess for their help in the pathology and enzyme studies; to Dr C. J. Hodson and Dr Elizabeth M. Haworth for their opinions on the radiological findings; to the N.E. Metropolitan Regional Hospital Board for a grant to E.M.P. to assist with research on malabsorption syndromes.

\section{REFERENCES}

Godenne, G. D., Burk, E. C., and Hallenbeck, G. A. (1957), Epiploic lipomatosis. Report of case. Proc, Mayo Clin., 32, 370-372. Lynn, H. B. (1964). Personal communication. 